\title{
Pengenalan English Vocabulary Pada Anak Usia Dini Melalui English For Kids
}

\author{
R. Agus Budiharto*1, S. Agus Santoso², Ratna Ani Lestari ${ }^{3}$ \\ 1Program Studi Pendidikan Bahasa Inggris, Fakultas Keguruan dan Ilmu Pendidikan, Universitas Madura, \\ 2Program Studi Administrasi Publik, Fakultas Ilmu Administrasi, Universitas Madura, Jl. Raya Panglegur \\ 3Program Studi Ilmu Politik, FSIP, Universitas Wijaya Kusuma Surabaya \\ *e-mail: budiharto@unira.ac.id
}

\begin{abstract}
Given the English vocabulary instructional method used by teachers of PAUD Qurrotul Uyun Pamekasan is not groundbreaking and varied since they constantly teach the English vocabulary from the textbook, additionally they never employ a modern technology tool such as smartphone gadget. Despite the fact that they frequently bring the gadget when the teaching learning porcoses in the class is occurring. In view of that the learning atmosphere becomes unappealing, the pupils becomes passive and dependent learners. Hence the aim of community service activity is to give pupils of PAUD Qurrotul Uyun Pamekasan training regarding English vocabulary learning employing English For Kids application. Method used in this community service is training by utilizing steps with activity theoretically and practically. The results are to be able to enhance pupils' leaning motivation, to be able to lessen pupils' boredom while learning, as well as to be able to create pulpils become autonomous pupils.
\end{abstract}

Keywords: English Vocabulary, English For Kids Application, Smartphone

\begin{abstract}
Abstrak
Mengingat metode guru PAUD Qurrotul Uyun Pamekasan saat mengajar tidak inovatif dan kurang variatif karena selalu mengajarkan kosakata bahasa Inggris dari buku pelajaran, tidak pernah memanfaatkan alat teknologi modern seperti gadget smartphone walupun sebenarnya guru sering kali membawa gadget tersebut saat proses pembelajaran sedang berlangsung. Dan hal ini mengakibatkan atmosfer pembelajaran jadi tidak menyenangkan, siswa menjadi pasif, dan tidak mandiri. Oleh karena itu maka tujuan kegiatan pengabdian ini dilaksanakan untuk melatih siswa PAUD Qurrotul Uyun Pamekasan mengenal dan belajar kosakata bahasa Inggris dengan menggunakan aplikasi English For Kids. Metode yang di pilih dalam kegiatan pengabdian ini berbentuk pelatihan dengan menggunakan tahapan kegiatan teoritis dan praktis. Hasil dari proses pelatihan pengenalan kosakata bahasa Inggris dengan menggunakan aplikasi English For Kids adalah dapat meningkatkan motivasi belajar siswa, dapat mengurangi rasa bosan siswa saat belajar, dan siswa dapat menjadi siswa yang mandiri dalam belajar.
\end{abstract}

Kata kunci: Kosakata Bahasa Inggris, Aplikasi English For Kids, Smartphone

\section{PENDAHULUAN}

Status bahasa Inggris sebagai bahasa pengantar dunia menyebabkan berbagai negara yang bahasa resminya bukan bahasa Inggris menerapkan kebijakan tentang adanya pendidikan bahasa Inggris di sekolah-sekolah. Dan pentingnya bahasa Inggris juga telah membuat banyak masyarakat dari berbagai kalangan di seluruh dunia belajar bahasa Inggris termasuk dari kalangnan anak-anak. Pinter \& Zandian (2015) menyatakan pada jaman ini banyak anak-anak sebagai pelajar muda belajar bahasa Inggris di sekolah Pendidikan Anak Usia Dini (PAUD), di Sekolah Dasar (SD) dan fenomena ini telah menjadi isu global di seluruh dunia. Pernyataan pakar tadi didukung oleh pernyataan Graddol (2006) bahwasannya usia di mana anak-anak diperkenalkan Bahasa Inggris di sekolah-sekolah juga semakin rendah di banyak wilayah di dunia sehingga mengakibatkan meningkatnya jumlah pelajar muda yang belajar bahasa Inggris. Di wilayah Asia-Pasifik contohnya di Hong Kong dan Taiwan bahasa Inggris diperkenalkan sebagai mata pelajaran wajib mulai kelas 1, di China dan Korea bahasa Inggris diperkenalkan mulai kelas 3 dan di Jepang dan Vietnam bahasa Inggris diperkenalkan mulai kelas 6 (Nunan, 2003). Sedangkan di Indonesia, sekalipun bahasa Inggris sebagai mata pelajaran wajib sudah 
diperkenalkan di Sekolah Menengah Pertama (SMP) mulai kelas 7, namun sekarang bahasa Inggris sudah diperkenalkan mulai sejak dini yaitu sejak anak-anak masuk sekolah PAUD. Ini didukung oleh banyak orang tua yang mendorong anak-anaknya untuk belajar bahasa Inggris pada usia dini dikarenakan mereka meyakini belajar bahasa Inggris lebih dini lebih baik (Bekleyen, 2011). Karena pada saat itu usia anak adalah masa periode yang penting (crtitical period) dan efektif untuk mengenal dan belajar bahasa atau kosakata baru.

Memperkenalkan suatu bahasa atau kata-kata baru pada anak sejak dini adalah hal yang sangat penting dan perlu dipelajari karena kata-kata merupakan komponen utama dalam penggunaan bahasa yang berfungsi sebagai alat komunikasi. Suatu hal yang tidak mungkin terjadi apabila belajar suatu bahasa tanpa didasarkan pada kata-kata / kosakata karena penguasaan kosakata adalah faktor sentral dalam pengajaran bahasa. Disamping itu, mengajarkan kosa kata adalah salah satu bagian yang paling banyak dibahas dalam pengajaran bahasa, seperti bahasa Inggris. Berkenaan dengan mengajarkan kosakata bahasa Inggris bagi siswa Indonesia untuk anak usia dini tentunya memerlukan banyak waktu, usaha, juga latihan. Ini dikarenakan sifat anak-anak yang gemar bermain daripada belajar. Juga cara pengucapan kosakata bahasa Inggris yang sangat berbeda dengan cara pengucapan kosakata bahasa Indonesia yang membuat mereka sulit belajar kosakata bahasa Inggris. Oleh sebab itu, sangat penting bagi guru yang ingin mengajarkan kosakata bahasa Inggris pada siswa didiknya untuk menggunakan strategi pembelajaran yang menarik dan menyenangkan agar anak-anak bisa belajar kosakata bahasa Inggris dengan mudah dan dapat mengembangkan aspek-aspek lain dari pengetahuan global mereka. Adapun pembelajaran kosakata bahasa Inggris dapat dipelajari dengan menerapkan teknologi. Karena menurut ide Pavlik (2015) hadirnya teknologi sekarang telah membawa perubahan besar dalam proses belajar mengajar, yaitu teknologi dapat memfasilitasi para individu untuk mencapai tujuan pembelajaran dengan berbagai perbedaan kemampuan yang mereka miliki, seperti kemampuan melihat, mendengar, membaca, menulis ataupun kemampuan memahami bahasa Inggris (Brand, Favazza, \& Dalton, 2012).

Berhubungan dengan penggunaan teknologi yang bisa di gabungkan dengan suatu pembelajaran, seperti pembelajaran kosakata bahasa Inggris, dapat mempunyai manfaat besar bagi siswa. Ketika teknologi diterapkan dengan tepat maka ini akan membuat pembelajaran lebih menyenangkan bagi siswa. Siswa merasa dapat terlibat aktif dalam mengikuti materi pembelajaran dan siswa juga merasa sangat terbantu untuk lebih memahami materi dengan baik melalui teknologi (Billings and Mathison, 2011). Akan tetapi manfaat-manfaat tadi tidak di dapatkan oleh kami selaku Tim Pengabdian masyarakat Universitas Madura ketika menadapatkan ijin dari pihak Sekolah PAUD Qurrotul Uyun Pamekasan pada tanggal $2 \mathrm{~s} / \mathrm{d} 7$ Desember 2019 untuk melakukan observasi saat guru melakukan kegiatan belajar mengajar di kelas. Guru sering kali duduk atau berdiri di depan siswa untuk menjelaskan materi bahasa Inggris melalui metode ceramah dengan papan tulis, boardmarker sebagai alat bantu dalam proses pembelajaran. Sedangkan menurut Susikaran (2013) metode pembelajaran melalui ceramah dengan alat bantu papan tulis, boardmarker dianggap kurang efektif untuk mengajar bahasa Inggris. Selain itu, metode guru saat mengajar tidak inovatif dan kurang variatif karena guru selalu mengajarkan kosakata bahasa Inggris dari buku pelajaran, tidak pernah mengajarkan kosakata bahasa Inggris dengan memanfaatkan alat teknologi modern seperti gadget smartphone walupun sebenarnya guru sering kali membawa gadget tersebut saat proses pembelajaran sedang berlangsung. Hal ini mengakibatkan atmosfer pembelajaran jadi tidak menyenangkan, siswa menjadi pasif, tidak kreatif dan tidak mandiri karena siswa harus selalu menggantungkan pada penjelasan guru (teacher-centred learning), siswa juga merasa tidak terbantu dan merasa kesulitan untuk memahami materi ketika diterangkan karena tidak hadirnya alat bantu teknologi modern dalam penjelasan guru. Temuan-temuan permasalahan tadi mendorong Tim Pengabdian untuk melakukan upaya dalam mengenalkan dan mengajarkan kosakata bahasa inggris pada siswa PAUD Qurrotul Uyun Pamekasan yang dikategorikan sebagai anak usia dini melalui aplikasi English For Kids sebagai solusi dari permasalahan yang ditemukan tadi. 


\section{METODE}

Kegiatan pengabdian pada masyarakat ini bertujuan untuk mengenalkan kosakata bahasa Inggris pada siswa PAUD Qurrotul Uyun Pamekasan yang berusia antara 4 - 5 tahun sebanyak 16 siswa sebagai sasaran utamanya dengan menggunakan aplikasi English For Kids dimana dalam aplikasi ini terdapat banyak metode permainan (game). Aplikasi ini merupakan aplikasi pembelajaran Bahasa Inggris yang banyak membahas kosakata bahasa Inggris dan di rancang untuk anak-anak yang berusia sekitar 3 sampai 7 tahun dalam bentuk permainanan. Oleh karena alasan itu aplikasi English For Kids yang terdapat banyak metode permainan di pilih oleh Tim Pengabdian dalam melaksanakan kegiatan pengabdiannya karena dalam penelitian Anyaegbu, Wei, and Yi (2012) di sebutkan bahwasannya anak-anak lebih suka belajar bahasa Inggris melalui permainan daripada melaui pembelajaran tradisional. Dalam aplikasi English For Kids juga memiliki gabungan audio dan visual yang sangat menarik tentang materi-materi pembelajaran kosakata bahasa inggris seperti: $A B C$ Course, Vocab Course, Expression, Vocabulary Lists dan lainlain yang di rancang dalam bentuk permainan. Dengan begitu anak-anak dapat belajar kosakata bahasa Inggris dengan santai sambil bermain.

Adapun lokasi pelaksanaan pengabdian ini dilaksanakan di dalam kelas sekolah PAUD Qurrotul Uyun Pamekasan selama 2 (dua) minggu dengan rincian yaitu 4 (empat) kali pertemuan dan pada setiap pertemuan berdurasi sekitar 1 (satu) jam 30 menit. Metode yang di pilih dalam kegiatan pengabdian ini berbentuk pelatihan dengan menggunakan tahapan kegiatan teoritis dan praktis. Pada kegiatan teoritis diawali dengan memberikan motivasi kepada siswa akan pentingnya belajar bahasa Ingggris dengan menggunakan aplikasi teknologi modern yaitu aplikasi English For Kids sebagai cara yang menyenangkan dalam belajar kosakata bahasa Ingggris. Kemudian siswa diberikan informasi mengenai aplikasi tersebut beserta cara-cara penggunaannya dalam mempelajari kosakata bahasa Inggris. Sedangkan pada kegiatan praktis siswa diminta untuk mempraktekkan aplikasi English For Kids dimana sebelumnya Tim Pengabdian telah mempresentasikan dan memberikan contoh bagaimana cara menggunakan aplikasi English For Kids. Namun sebelum kegiatan praktis dilaksanakan Tim Pengabdian menginformasikan pada siswa untuk membawa smartphone android saat pelatihan dan kemudian Tim Pengabdian membantu siswa untuk mengistalkan aplikasi tersebut. Kegiatan praktis ini dilakukuan dengan tujuan agar siswa terampil dalam menggunakan aplikasi English For Kids dalam belajar kosakata bahasa Inggris.

\section{HASIL DAN PEMBAHASAN}

Kegiatan pengabdian kepada masyarakat ini bertujuan tidak hanya memberikan pengetahuan pada siswa PAUD Qurrotul Uyun Pamekasan tentang aplikasi English For Kids yang dapat di gunakan untuk belajar kosakata bahasa Inggris tetapi juga dapat melatih ketrampilan siswa dalam memanfaatkan aplikasi English For Kids melalui gadget virtual yaitu smartphone android agar mereka tidak gaptek teknonologi. Hal ini didukung oleh pernyataan Oktavia dkk (2019) dalam kegiatan pengabdian mereka bahwasannya untuk meningkatkan kemahiran individu dalam menggunakan bahasa Inggris diperlukan adanya teknologi android. Kegiatan pengabdian ini dilaksanakan sesuai dengan rencana yang telah direncanakan sebelumnya yaitu sebanyak 4 (empat) kali pertemuan tepatnya pada tanggal 4, 6, 11, 13 Februari 2020, dari jam 08.00 wib sampai jam 09.30 wib. Langkah awal yang di lakukan oleh Tim Pengabdian dalam melaksanakan kegiatan ini adalah dengan menyebarkan undangan kepada para siswa melalui orang tua / wali murid mereka dimana dalam undangan tersebut, diberitahukan bahwa setiap siswa diharuskan membawa smartphone android. 
Tabel 1. Data siswa PAUD Qurrotul Uyun Pamekasan yang hadir waktu pelatihan

\begin{tabular}{lllll}
\hline No & Nama Siswa & Nama Orang Tua & Pekerjaan Orang Tua & Alamat \\
\hline 1 & Atiqatul Maula & Moh Wardi & Wira Swasta & Trasak \\
2 & Imamatus Sofiyah & Moh Fauzan & Petani & Trasak \\
3 & Anisatur Rofiqoh & Siti Maisaroh & Petani & Tentenan Barat \\
4 & Ayyobi Mu'arif & Jauhari & Karyawan Swasta & Trasak \\
5 & Moh Jufriyadi & Moh Sagi & Petani & Trasak \\
6 & Fahri Al-Farobi & Junaidi & Petani & Tobungan \\
7 & Deviy Kamelia & Misbahul & Peternak & Trasak \\
8 & Afdal Fathul Bahri & Jubriyadi & Wira Swasta & Trasak \\
9 & Adril Warid & Masyhuri & Peternak & Trasak \\
10 & Nur Ilmi Ridhaullah & Hosnan & Petani & Trasak \\
11 & Nafilatus Ziadah & Djatim & Petani & Trasak \\
12 & Juliana Ramadhani & Armito & Karyawan Swasta & Trasak \\
13 & Rizal Firdaus & Muhdar & Karyawan Swasta & Tobungan \\
14 & Risalutul Ummah & Bakir & Petani & Tentenan Barat \\
15 & Qodrun Salsabiela & Supriyadi & Wira Swasta & Tentenan Barat \\
16 & Syaiful Anam & Hasan & Petani & Trasak \\
\hline
\end{tabular}

Hasil dari undangan yang di sebarkan direspon sangat positif oleh para siswa termasuk para orang tua mereka, hal ini bisa di buktikan dari data saat para siswa datang bersama orang tuanya. Mereka menghaidri ke tempat pelatihan dengan antusias dan jumlah siswa yang datang sesuai dengan harapan Tim pengabdian yaitu 16 (enam belas) siswa. Sekalipun siswa yang datang ke tempat pelatihan di damping orang tuanya masing - masing akan tetapi orang tua mereka tidak di perkenankan masuk ke dalam kelas saat kegiatan pengabdian berlangsung. Mereka hanya di perbolehkan menunggu di luar kelas atau menyaksikan pelaksanaan kegiatan pengabdian dari luar kelas. Hal ini di lakukan agar siswa / putra - putri mereka menjadi siswa mandiri dan bisa lebih berkonsentrasi pada materi pelatihan yang di berikan saat kegiatan pengabdian berlangsung.

Pada tanggal 4 Februari 2020 merupakan kegiatan pengabdian yang pertama. Kegiatan ini dilaksanakan dari jam 08.00 s/d 09.30 WIB. Kegiatan diawali dengan memberikan sambutan sekaligus perkenalan oleh ketua Tim Pengabdian pada para siswa. Kemudian Ketua Tim beserta anggota lainnya secara bergantian memberikan motivasi dan informasi penting pada para siswa tentang perlunya memiliki ketrampilan berbahasa Inggris pada jaman teknologi modern ini. Siswa juga diberikan pengetahuan dan keyakinan bahwa untuk menguasai bahasa Inggris sangatlah mudah dan untuk memulai belajar bahasa Inggris haruslah dari kosakata terlebih dahulu. Walupun saat Tim Pengabdian memaparkan hal - hal tersebut hampir dari semua siswa menyatakan bahwa bahasa Inggris adalah bahasa planet yang sangat susah untuk dimengerti dan dipelajari. Setelah itu Tim Pengabdian menyampaikan pentingnya penggunaan aplikasi teknologi pada era modern dalam belajar bahasa Ingggris salah satunya yaitu aplikasi English For Kids. Aplikasi ini kemudian di informasikan pada siswa sebagai cara yang menyenangkan dan cara yang sangat mudah untuk belajar kosakata bahasa Ingggris. Para siswa sangat senang dan begitu memperhatikan saat Tim Pengabdian memvisualisasikan cara belajar kosakata bahasa Inggris dengan menggunakan aplikasi English For Kids melalui smartphone android yang sudah terhubung dengan LCD, seperti menginstal aplikasi terlebih dahulu, menulis nama sendiri dan memilih gambar ketika aplikasi sudah terinstal dan kemudian memilih item kosakata bahasa Inggris pada menu yang sudah tersedia. Setelah itu para siswa di berikan kesempatan untuk bertanya terkait dengan keterangan presentasi Tim Pengabdian. 


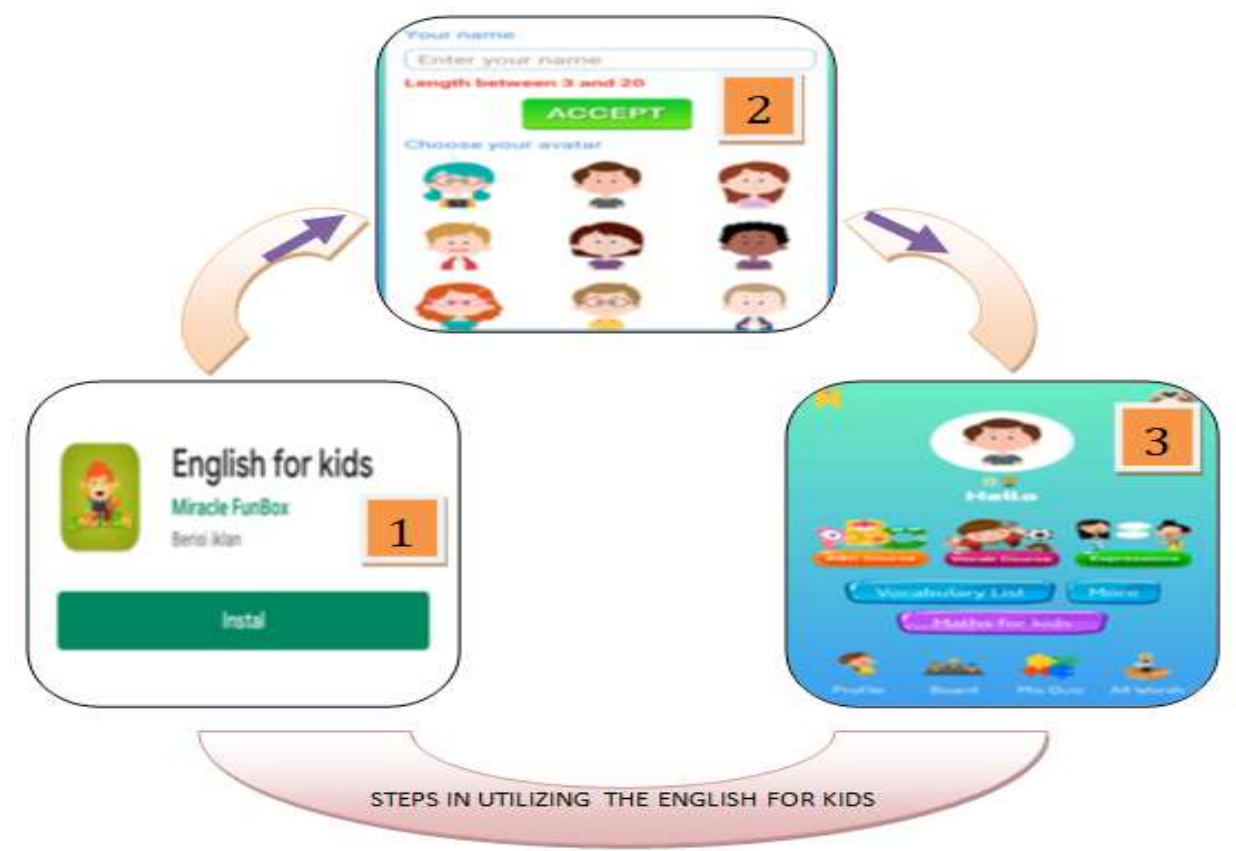

Gambar 1. Cara-cara menggunakan aplikasi English For Kids

Pada tanggal 6 Februari 2020 Tim Pengabdian menjelaskan pada seluruh siswa 1 (satu) contoh permainanan English vocabulary yang terdapat pada aplikasi English For Kids yaitu bagaiamana cara mengoperasikan permaianan $A B C$ Course (dapat di lihat pada Gambar2). Tim Pengabdian menggunakan waktu 1 (satu) jam untuk sesi menjelaskan kemudian siswa waktu 30 (tiga puluh) menit di gunakan untuk sesi tanya jawab. Dalam sesi menjelaskan Tim Pengabdian tidak lupa memberikan motivasi pada siswa untuk tidak takut melakukan kesalahan saat berlatih dalam belajar kosakata bahasa Inggris dan untuk terus berlatih dengan cara selalu mempraktekkannya baik di rumah maupun di sekolah.

Permaianan $A B C$ Course adalah suatu permainan untuk melatih ketrampilan anak dalam mengenal dan melafalkan huruf abjad bahasa Inggris. Dalam permainan ini anak bisa mengetuk tanda bila ingin mengetahui cara melafalkan suatu huruf dengan benar dalam bahasa Inggris. Anak juga tidak perlu kuwatir ketika melakukan kesalahan dalam balajar huruf abjad bahasa Inggris di $A B C$ Course ini karena secara otomatis system memberikan kesempatan lagi untuk mengulangnya lagi dengan tanda WRONG - TRY AGAIN

Dengan adanya tanda-tanda seperti itu, di harapkan anak-anak menjadi senang dan lebih termotivasi untuk belajar kosakata bahasa Inggris dengan menggunakan aplikasi English For Kids. Karena mereka merasa terbantu menemukan jalan keluar ketika mereka mendapatkan kesulitan saat belajar kosakata bahasa Inggris. Setelah Tim Pengabdian menjelaskan cara mengoperasikan permaianan $A B C$ Course kemudian semua siswa di beritahukan bahwa sisa dari permainan yang lain bisa di praktekkan sendiri oleh mereka di rumah mereka atau di sekolah agar mereka bisa melatih sendiri untuk memperoleh ketrampilan kosakata bahasa Inggris. 


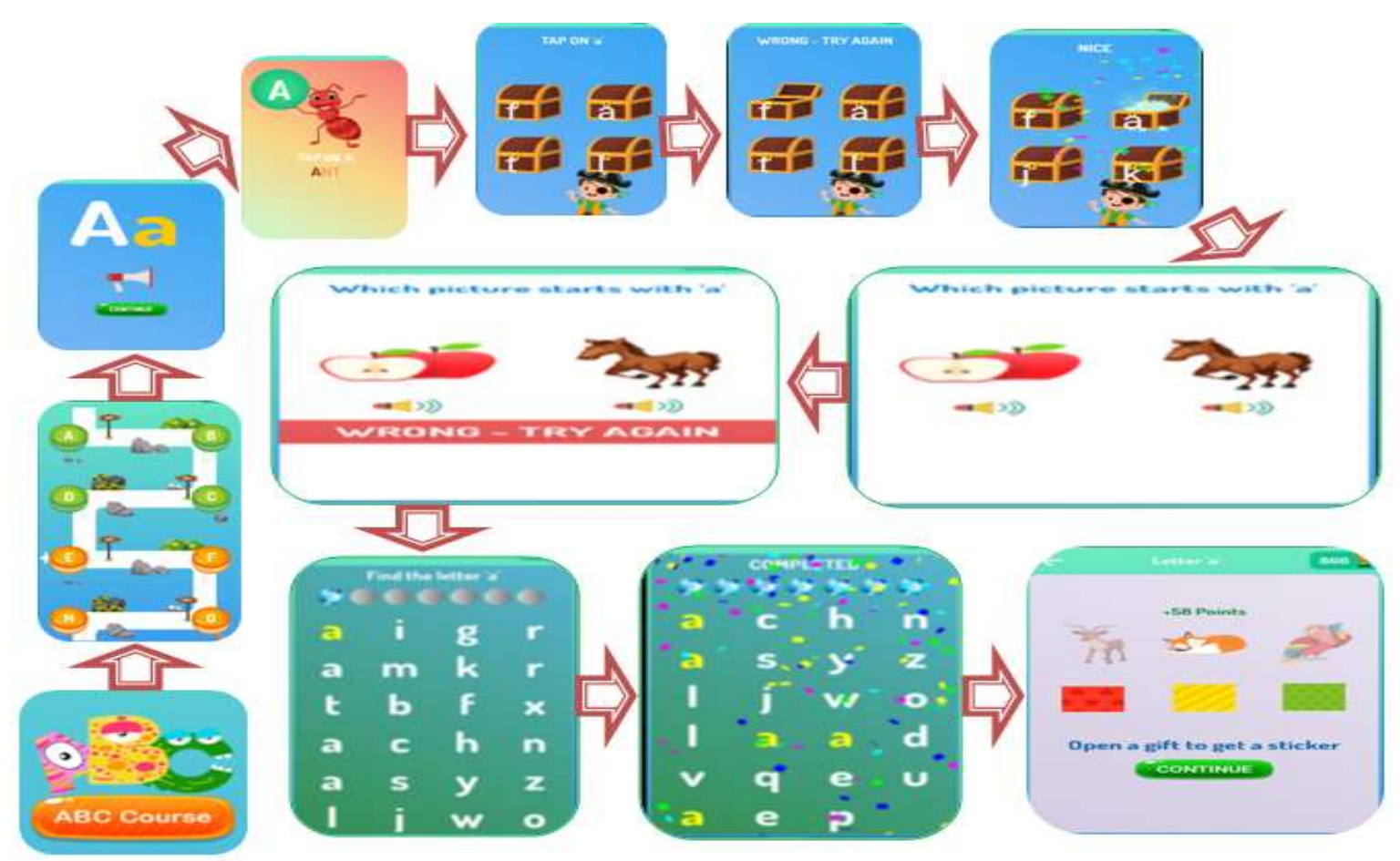

Gambar 2. Cara-cara mengoperasikan permaianan ABC Course

Pada tanggal 11 Februari 2020 merupakan pertemuan kegiatan pengabdian ke tiga dalam pelatihan pengenalan kosakata bahasa Inggris bagi siswa PAUD Qurrotul Uyun Pamekasan. Pada pertemuan ini, Tim Pengabdian memberikan kesempatan pada para siswa untuk mencoba sendiri berlatih belajar kosakata bahasa Inggris dari menu aplikasi English For Kids yang sudah di contohkan dan di jelaskan oleh Tim Pengabdian sebelumnya. Setelah itu para siswa di instruksikan untuk berlatih menu kosakata yang lain yang terdapat pada aplikasi English For Kids karena Tim Pengabdian merasa keterangan detail dan presentasi yang di berikan pada pelatihan kedua sudah dapat membuat para siswa cukup paham tentang cara-cara menggunakan aplikasi English For Kids melalui smartphone android. Dalam melaksanakan kegiatan ini, Tim Pengabdian sebelumnya mengumumkan pada semua siswa untuk wajib membawa smartphone android. Walaupun saat pelatihan ada beberapa siswa sebanyak 5 (lima) orang yang tidak membawa smartphone android dikarenakan mereka tidak punya alat gadget tersebut. Sekalipun demikian kegiatan pelatihan tetap dilaksanakan sesuai dengan jadwal yaitu dari jam $08.00 \mathrm{~s} / \mathrm{d} 09.30 \mathrm{WIB}$ dan siswa yang tidak membawa smartphone android di himbau untuk bergabung dengan teman mereka yang membawanya, serta disarankan untuk membawa alat gadget tersebut pada pertemuan berikutnya dengan cara meminjam alat teknonologi modern tersebut ke teman atau tetanggannya. Pada sesi pelatihan ini Tim Pengabdian juga melakukan pendampingan pada siswa yang sedang berlatih belajar kosakata bahasa Inggris dengan menggunakan aplikasi English For Kids dengan cara memberikan bimbingan dan penjelasan pada siswa-siswa yang mengalami kesulitan dalam mengoperasikan aplikasi English For Kids. Dan sebelum pelatihan ini di akhiri, para siswa di minta untuk berlatih sendiri di rumah mereka tentang pembelajaran kosakata bahasa Inggris dengan menggunakan aplikasi English For Kids dengan tujuan agar siswa menjadi siswa yang lebih mandiri dalam melakukan kegiatan pembelajaran bahasa Inggris terutama dalam belajar kosakata.

Pada tanggal 13 Februari 2020 para siswa di minta untuk mempraktekkan lagi cara belajar kosakata bahasa Inggris dengan menggunakan aplikasi English For Kids. Hal ini dilakukan untuk meyakinkan bahwa para siswa tidak ada yang mengalami kesulitan dalam mengoperasikan aplikasi English For Kids serta untuk memaksimalkan ketrampilan dan pengetahuan mereka dalam belajar kosakata bahasa Inggris dengan menggunakan aplikasi English For Kids. Selain itu, 
alasan Tim Pengabdian meminta para siswa untuk mempraktekkan lagi aplikasi English For Kids agar mereka mengetahui bahwa ketika belajar kosakata bahasa Inggris dengan menggunakan aplikasi English For Kids tanpa mereka sadari mereka juga mendapatkan pengetahuan lain dari aplikasi tersebut seperti mendapatkan ketrampilan melafalkan kata bahasa Inggris (pronunciation) dengan benar, ketrampilan mendengarkan kata bahasa Inggris (listening) serta ketrampilan membaca kata bahasa Inggris (reading) sehingga hal ini dapat membantu mereka dalam meningkatkan ketrampilan bahasa Inggris mereka.

\section{KESIMPULAN}

Proses pelatihan pengenalan kosakata bahasa Inggris dalam kegiatan pengabdian ini dilakukan dengan menggunakan alat teknologi modern yaitu aplikasi English For Kids sebagai alat pedagogi yang menarik, menyenangkan sekaligus efektif dalam membantu memudahkan siswa PAUD Qurrotul Uyun Pamekasan dalam belajar kosakata bahasa Inggris. Aplikasi English For Kids yang di lengkapi dengan gabungan audio dan visual yang sangat menarik tentang materi-materi pembelajaran kosakata bahasa inggris merupakan media pembelajaran yang terdapat banyak metode permainan (game) di dalamnya yang dapat befungsi untuk mencegah kebosanan anak ketika sedang terlibat dalam suatu kegiatan pembelajaran, berfungsi untuk meningkatkan motivasi belajar anak dan juga dapat berfungsi untuk memperkaya perbendaharaan kosakata bahasa Inggris yang dapat di jadikan sebagai komponen utama dalam kemampuan berkomunikasi.

\section{DAFTAR PUSTAKA}

Anyaegbu, R., Wei , T., \& Yi, L. (2012). Serious game motivation in an EFL classroom in Chinese primary school.Turkish Online Journal of Educational Technology, 11 (1), 154 - 164.

Bekleyen, N. (2011). Can I teach English to children? Turkish preservice teacher candidates and very young learners. Journal of Early Childhood Teacher Education, 32, 256-265.

Billings, E., \& Mathison, C. (2011). I get to use an iPod in school? Using technology-based advance organizers to support the academic success of English Learners. Journal of Science Education Technology, 21(4), 494-503.

Brand, S., Favazza, A. E., \& Dalton, E. M. (2012). Universal design for learning: A blueprint or success for all learners. Kappa Delta Pi Record , 48 (3), 134 - 139.

Graddol, D. (2006). English next. Retrieved February 10, 2020, from www.britishcouncil.org/files/documents/learning-research-english-next.pdf.

Nunan, D. (2003). The impact of English as a global language on educational policies and practices in the Asia-Pacific region. TESOL Quarterly, 37 (4), 589-613.

Pinter, A., \& Zandian, S. (2013). 'I don't ever want to leave this room:' benefits of researching 'with' children. ELT Journal, 68, 64-74.

Oktavia, Y., Eka Putra, E., Silalahi, M., (2019). Pembinaan Budaya Literasi Berbasis Android Untuk Kemahiran Bahasa Inggris Dan Kesantunan Berbahasa. DINAMISIA - Jurnal Pengabdian Kepada Masyarakat, 3, 90-100.

Pavlik, J. V. (2015). Fueling a third paradigm of education: The pedagogical implications of digital, social and mobile media. Contemporary Educational Technology, 6(2), 113-125.

Susikaran, R. S. A. (2013). The use of multimedia in English language teaching. Journal of Technology for ELT, 3 (2). 